\title{
LAS MUERTES DE BAJO PISAGUA EN 1906. NUEVOS ANTECEDENTES PARA LA COMPRENSION DE LA TRAGEDIA
}

MATEO MARTINIC B.

\section{RESUMEN}

Se entrega una noticia hasta ahora desconocida sobre la mortandad acaecida en Bajo Pisagua, zona del Baker, en 1906, que permite una mejor comprensión acerca del lamentable suceso referido a la colonización original.

PALABRAS CLAVE: Patagonia, colonización, tragedia sanitaria.

\section{THE 1906 BAJO PISAGUA DEATHS. NEW INFORMATION FOR THE COMPREHENSION OF THE TRAGEDY}

\begin{abstract}
An unknown news about the mortality happened in Bajo Piragua, Baker zone, in 1906 is delivered, allowing a better comprehension of this tragic event that referrers to the initial settling in the area.

KEY WORDS: Patagonia, colonization, health tragedy.

\section{INTRODUCCION}

Los sucesos acaecidos durante el curso de 1906 en Bajo Pisagua, el primero de los centros de actividad colonizadora de la Compañía Explotadora del Baker, y de los que fueron protagonistas los trabajadores que allí permanecían durante el invierno de ese año, mientras aguardaban ser recogidos por un vapor que debía trasladarlos a Chiloé, y que dieron por resultado el fallecimiento, de manera masiva

y rápida, de una sesentena de trabajadores, han sido materia de controversia entre cuantos se han ocupado del asunto de un siglo a esta parte.

Desde un principio y por largo tiempo la forma en que se dio ese fenómeno sanitario, por calificarlo de algún modo, aparentemente sin una explicación razonable, con mucho de misterio, dio origen a rumores que pasaron de boca en boca y que a la vuelta de tres o más décadas fueron recogidos por algunos y dados por veraces. Entonces se dijo
\end{abstract}

* Profesor Emérito. Centro de Estudios del Hombre Austral, Instituto de la Patagonia, Universidad de Magallanes. Correo electrónico: magallania@umag.cl 
y repitió acerca de un supuesto envenenamiento colectivo intencional, hecho criminal del que había sido responsable la dirigencia de la Compañía del Baker, para ahorrarse así el pago de haberes devengados por los fallecidos durante el tiempo en que habían trabajado en las faenas madereras, para las que habían sido contratados en Puerto Montt. Igualmente se habló de una hambruna y de una intoxicación accidental como posibles causas de tal mortandad.

Otros, como el explorador Alberto M. De Agostini y el viajero suizo Aimé Tschiffely, enterados del suceso se resistieron a creer semejante imputación y prefirieron interpretar el hecho, también sobre la base de algunas noticias, como una epidemia fulminante y mortal que se abatió sobre los trabajadores. Inclusive se afirmó que se había tratado de escorbuto, el conocido y estragador mal de otras épocas, responsable de tantas víctimas durante los prolongados periplos marinos de antaño.

El asunto, bien se sabe, quedó virtualmente aclarado hace pocos años una vez que en 1998 los arqueólogos Francisco Mena y Héctor Velásquez realizaron un estudio científico con los restos humanos depositados en el cementerio de la isla de los Muertos, en el estuario del río Baker, y concluyeron que las evidencias permitían suponer una intoxicación casual acompañada por una hambruna, más que por una acción deliberada de envenenamiento. Se determinó, asimismo, que los restos allí encontrados permitían calcular que se trataba de entre 60 y 80 individuos.

Luego, en 2000, la investigadora Danka Ivanoff encontró y publicó algunas cartas inéditas de William Norris, antiguo capataz general o administrador de la Compañía del Baker, en las que se daba cuenta de lo ocurrido en Bajo Pisagua entre los meses de agosto y setiembre de 1906, así como otras informaciones referidas a la actividad colonizadora en el distrito. En ellas Norris afirmaba que la tragedia sanitaria había sido provocada por la carencia de alimentos, seguida de escorbuto, con resultados de 57 hombres fallecidos en el lugar y otros dos con posterioridad.

De esa manera vino a aclararse virtualmente un misterio y a aventarse un injustificado infundio sobre la memoria de los ejecutivos responsables de la fallida empresa colonizadora inicial en el distrito inferior del Baker.

\section{UN NUEVO ANTECEDENTE PARA LA MEJOR COMPRENSION DEL TRAGICO SUCESO}

En noviembre de 1907, esto es, poco más de un año después de aquel acontecimiento, recaló en Bajo Pisagua Charles A. Milward, cónsul del Imperio Británico en Magallanes, de paso para Puerto Montt embarcado en el vapor Alm de la compañía naviera Braun \& Blanchard, quien posteriormente escribiría un relato sobre su viaje de conocimiento a la región del río Aysén, publicado en The Punta Arenas Mail, un periódico publicado en inglés, en el que dejó constancia de sus observaciones e impresiones sobre el lugar, de la siguiente manera:

El día 13 llegamos a Río Baker, un lugar desolado como nunca lo había visto. No pudimos acercarnos mucho, porque el río arrastraba su carga de arena, barro, troncos y ramas de árboles, etc. con escaso fondo, con resultado tal que en un minuto Ud. tenía 40 brazas de agua y en el largo del barco poco más allá había sólo 2 brazas. Largamos el ancla finalmente y alrededor de una hora después vino a bordo el administrador. Tomamos allí carga y algunos pasajeros; entre ellos estaba Mr. W. Morris [sic] quien dirigía la Compañía Baker desde un principio y había soportado tiempos difíciles. Una vez tuvo 87 hombres enfermos entre más de 200 a su cargo y los sanos no quisieron atender a sus camaradas enfermos gratuitamente, y por un insignificante vaso de agua se cobraba una tarifa de 10 cts., pero por llevar comida desde la cocina-algunos 60 pies [aproximadamente 20 metros]-en la mañana y en la tarde, y dar vuelta a los enfermos en sus camas era 50 cts.; aquí no había sacerdote y los conductores [headmen] que acostumbraban realizar los servicios religiosos en Chiloé cuando no estaba el sacerdote ${ }^{1}$, cobraban $\$ 2,50$ por las oraciones que debían ser ofrecidas por las almas de aquellos que fallecían; y los pobres infortunados que padecían fueron exigidos a pagar mientras sus almas abandonaban sus cuerpos, y en varias oportunidades cuando algunos se hallaban muy débiles para pagar o para firmar una orden

1 Referencia a los "fiscales" o ayudantes que durante las antiguas rondas misionales de los jesuitas en el curso de los siglos XVII y XVIII en Chiloé asumían la conducción de algunos oficios religiosos en ausencia y por encargo del sacerdote, oficio mantenido por tradición hasta la actualidad. 
de pago eran tirados a la fosa como perros. En una ocasión murieron 67 de escorbuto, etc.

El establecimiento principal [conocido como La Colonia] está a 8 días de distancia en un bote ballenero; en el puerto no había nada excepto la oficina, con un almacén y la madera que cortaba la gente de Chiloé. Dejamos el Baker sin sentimiento y alcanzamos Quellen [Quellón] el 16 de Noviembre a las 0,30 p.m. El Capitán de Puerto vino a bordo y dijo que el "Westfold" en el cual yo debía proseguir el viaje no había arribado. El Domingo descargamos la poca carga que traíamos y recibimos otra para el siguiente puerto de Quailen [Queilen] 3 .

Lo transcrito conforma un antecedente hasta ahora desconocido, proveniente de un observador independiente, sobre el suceso que se comenta y que pone de manifiesto la actitud asumida por algunos trabajadores que en tan crítica circunstancia por la que pasaban poco menos de un centenar de compañeros, lejos de colaborar para su mejor asistencia en el duro trance por el que pasaban, se negaron a hacerlo a menos que se les pagara por tal auxilio $e$ inclusive hasta para decir algunas oraciones en las tumbas de los fallecidos. En buenas cuentas, se había tratado de lucrar a costa del padecimiento o la desgracia ajenos.

¿En verdad pudo ser así, como lo asevera Milward basado en los dichos de Norris? Lejos de parecer una invención suya, nos parece que más bien

2 Esta nave junto con el Alm pertenecían a la insignia de la casa armadora y comercial Braun \& Blanchard de Punta Arenas, con las que la misma había dado inicio a la línea regular de cabotaje entre ese puerto y Valparaíso a comienzos de 1907.

3 "Some account of a trip up the river Aysen", en The Punta Arenas Mail, edición del 15 de enero de 1908. Traducción del autor. lo escrito debió ajustarse a lo realmente acontecido entonces. De haber sido así, se tiene muy clara una manifestación de insolidaridad de parte de algunos obreros sanos respecto de sus compañeros enfermos. Si de primera ello pudo ser motivado por el temor a un supuesto contagio, ante la incertidumbre que había respecto de qué clase de enfermedad se trataba, tal suposición se invalida cuando aparece el afán de lucro del que se ha dado cuenta. Es un caso que bien puede ser calificado de inhumano que, si se dio como aparece, pudo contribuir, de manera cierta, a que la enfermedad colectiva que afectaba a los ochenta y tantos obreros acabara por ser la tragedia que la historia ha recogido. Duro de aceptar, pero, al parecer, así sucedió.

La miseria moral que puede esconderse en algún recóndito pliegue del alma humana, en determinadas circunstancias de apremio o necesidad extremos puede aflorar, cobrar expresión y vigencia, con resultados como los dados a conocer en esta comunicación.

\section{FUENTES DE CONSULTA}

AgOSTINI, ALBERTO M. DE 1945 Andes Patagónicos. Editorial SEI. Buenos Aires.

IVANOFF WELLMANN, DANKA 2000 Caleta Tortel y su Isla de los Muertos. Municipalidad de Caleta Tortel, Región de Aysén. Chile Chico.

MARTINIC B., MATEO 2005 De la Trapananda al Áysen. Pehuén Editores, Santiago.

MENA, FRANCISCO y HÉCTOR VELÁSQUEZ 2000 Isla de los Muertos: Mito y realidad. Anales del Instituto de la Patagonia, Serie Ciencias Humanas, vol. 28: 53-72. Punta Arenas.

MILWARD, CHARLES A. 1908 "Some account of a trip up the river Aysen". The Punta Arenas Mail, January 15th, 1908. Punta Arenas. 
